\title{
A mobilização do conhecimento pedagógico do conteúdo sobre o cientista e a ciência: análise de uma sequência didática produzida por uma futura professora de ciências
}

\section{The mobilization of pedagogical content knowledge about scientist and science: analysis of a didactic sequence produced by a future sciences teacher}

\author{
Boniek Venceslau da Cruz Silva ${ }^{1}$ \\ Universidade Federal do Piauí
}

\begin{abstract}
RESUMO
Este trabalho relata indícios da mobilização do conhecimento pedagógico do conteúdo sobre o cientista e a Ciência de uma futura professora de Ciências da Natureza, quando solicitada a construir uma sequência didática para estudantes do ensino fundamental. Entende-se como conhecimento pedagógico do conteúdo (Pedagogical Content Knowledge - PCK, em inglês), o amálgama entre o conteúdo e a pedagogia (Shulman, 1987). Ou seja, a transformação dos conteúdos científicos, no nosso caso metacientíficos, em conteúdos ensináveis aos estudantes. Em especial, neste trabalho, para compreender a mobilização do PCK da futura professora, utilizamos a proposta de Silva e Martins (2018; 2019) que visa avaliar a mobilização do PCK sobre a Natureza da Ciência (PCK/NdC) em futuros professores de Ciências. Com base na sequência didática produzida e pelo preenchimento de um questionário específico para acessar indícios do PCK, notamos que a produção de sequências didáticas configurase como uma ferramenta para o estudo da mobilização do $\mathrm{PCK} / \mathrm{NdC}$, enaltecendo às diferentes relações entre os conhecimentos, com destaque para os de currículo, avaliação e compreensão de Ciência dos estudantes, para a execução da tarefa. Por fim, sugerimos que atividades como esta possam ser incentivadas na formação de futuros professores de Ciências, pois podem apresentar indícios das deficiências e qualidades do PCK/ $\mathrm{NdC}$, favorecendo o ofício de docentes formadores no trabalho da produção de estratégias didáticas que tenham a finalidade de ensinar temas sobre a natureza da Ciência.
\end{abstract}

Palavras-chave: Natureza da Ciência; Concepção do Cientista e da Ciência; Professores de Ciência em formação

\begin{abstract}
This paper reports evidence of the mobilization of pedagogical content knowledge about the scientist and the Science of a future natural sciences teacher, when asked to build a didactic sequence for elementary school students. The Pedagogical Content Knowledge - PCK is understood as the amalgam between content and pedagogy (Shulman, 1987). In other words, the transformation of scientific content, in this paper case "meta-scientific", into content that can be taught to students. In particular, in this paper, we research to understand the mobilization of the PCK of the future teacher, we use the proposal of Silva and Martins $(2018 ; 2019)$ that aims to evaluate the mobilization of the PCK on the Nature of Science (PCK / NOS) in future science teachers. Based on the didactic sequence produced and by completing a specific questionnaire to access evidence from the PCK, we note that the production of didactic sequences is configured as a tool for the study of the mobilization of the PCK / NOS, highlighting the different relationships between knowledge, with emphasis on students' curriculum, assessment and understanding of Science, for the execution of the task. Finally, we suggest that activities like this can be encouraged in the training of future science teachers, as they may show evidence of the deficiencies and qualities of the PCK / NOS, favoring the profession of teacher educators in the work of producing didactic strategies that have the purpose of teach topics about the nature of science.
\end{abstract}

Keywords: Nature of Science; Scientific and Science Conception; Initial Science Teachers.

\footnotetext{
${ }^{1}$ Doutorado em Ensino de Ciências e Matemática pela Universidade Federal do Rio Grande do Norte (UFRN). Professor Adjunto na Universidade Federal do Piauí (UFPI), Teresina, Piauí, Brasil. Endereço para correspondência: Residencial Jardins do Leste, Teresina, Piauí. CEP: 64034-570. ORCID iD: https://orcid.org/0000-0002-1648-2652. E-mail: boniek@ufpi.edu.br.
} 
Caderno de Pesquisa em Ensino

de Ciências e Matemática

\section{INTRODUÇÃO}

O professor, mesmo durante a sua formação, ao praticar o seu futuro ofício, mobiliza diferentes conhecimentos, crenças, valores, impressões sobre o que ensina, quem ensina e o seu contexto de aprendizagem (Silva; Martins, 2019). O futuro professor, por exemplo, ao organizar uma sequência didática, mobiliza conhecimentos adquiridos no sentido de construir mecanismos metodológicos de ensino e de avaliação de seus estudantes, citando apenas alguns.

Assim, parece-nos que o professor, seja em formação ou em exercício, possui um leque vasto de conhecimentos mobilizados ao exercer (ou praticar) o seu ofício. Embora exista na literatura especializada uma ampla definição para esse conjunto de conhecimentos, neste trabalho, em especial, adotaremos a noção de conhecimento de base para o ensino de Shulman (1986; 1987).

No seu artigo Those Who understand: knowledge growth in teaching, Shulman (1986) sinaliza a existência de três categorias relativas ao conhecimento para os professores: Conhecimento do conteúdo específico, Conhecimento do currículo e Conhecimento pedagógico para o conteúdo.

Já no seu artigo Knowledge and teaching: foundations of the new reform, Shulman (1987) insere o conhecimento pedagógico do conteúdo (Pedagogical Content Knowledge, PCK, em inglês) como um dos sete conhecimentos necessários para o professor. São eles: 1. Conhecimento de Conteúdo; 2. Conhecimento Pedagógico Geral; 3. Conhecimento Pedagógico do Conteúdo; 4. Conhecimento dos Aprendizes; 5. Conhecimento Curricular; 6. Conhecimento dos Contextos Educacionais e 7. Conhecimento dos Fins Educacionais.

Como descreve Bolivar (2005), Shulman tinha por objetivo explicar e desenvolver os componentes do conhecimento de base para o ensino. Além disso, objetivava também investigar o desenvolvimento do conhecimento profissional tanto na formação do professor como no seu ofício laboral, com destaque para como os professores transformavam o conteúdo da disciplina em representações didáticas para a sala de aula. Ou seja, o objetivo e o enfoque da sua investigação residiam na reivindicação do ensino como profissão. Para ele, os professores eram detentores de um corpo de conhecimentos para o ensino; o que o pesquisador, mais tarde, chamaria de conhecimento de base para o ensino. Neste artigo, em especial, adotaremos a noção de PCK de Shulman.

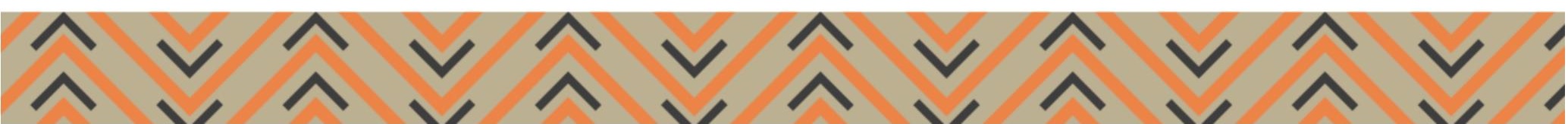


A definição de PCK foi alvo de várias pesquisas e na literatura especializada podemos encontrar diversas propostas de conceituação para ele. Inicialmente, Shulman o define como o amálgama entre o conteúdo e a pedagogia. Outros pesquisadores contribuem, por exemplo, para Grossman (1990), ele é o resultado da transformação de conhecimentos do contexto, do conteúdo e pedagógico.

Magnusson, Krajcik e Borko (1999) definem o PCK como a transformação de vários conhecimentos para ensinar. Ele representa o domínio efetivo do professor. Inclui o conhecimento particular dos tópicos, problemas, de como os métodos de ensino podem ser organizados, representados e adaptados para diversos interesses de aprendizagens e de como são apresentados para a sua instrução.

Baxter e Lederman (1999) dizem que o PCK é tanto um constructo interno como externo. Ele é constituído pelo o que professor sabe, pelo o que o professor faz e as razões para suas ações.

Para Kind (2009), o PCK traduz os conhecimentos que afloram no professor durante o processo de ensino. Ou seja, ele toma corpo no momento que o futuro professor ou professor experiente planeja sua aula, no material que ele escolhe para o planejamento e em como ele o utiliza na aula, no momento da avaliação de seus estudantes, dentre outros.

Para Silva (2018), ele configura-se como uma transformação de conhecimentos da base de ensino do professor, sejam em formação ou em exercício, e se desenvolvem a partir de práticas reflexivas nas quais os docentes são expostos no seu labor diário. Uma síntese da definição de Silva (2018) é exposta na figura 1. 
Figura 1 - Modelo Transformativo-reflexivo do PCK.

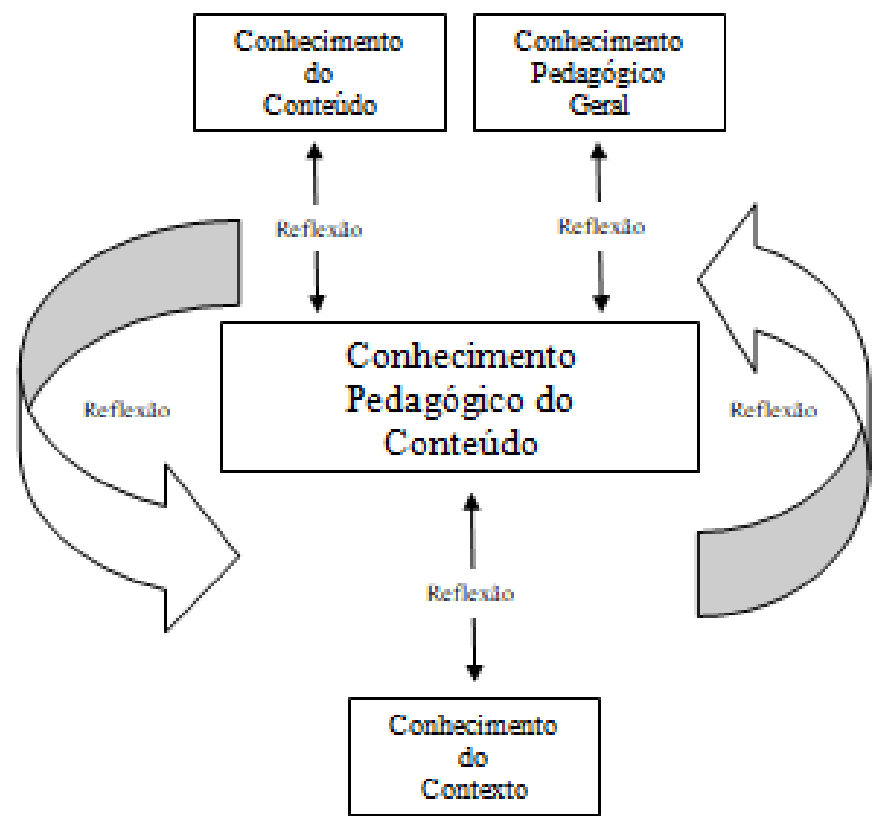

Fonte: [Extraído de Silva, 2018, p.67]

Neste trabalho, vamos ao encontro das definições dos autores que entendem o PCK como uma transformação de conhecimentos da base de ensino do professor. Em particular, temos como objetivo compreender como uma futura professora de Ciências da Natureza mobiliza o seu PCK sobre o cientista e a Ciência, ao construir uma sequência didática, com finalidades de ensinar temas sobre a Ciência no ensino fundamental.

\section{A CONCEPÇÃO DO CIENTISTA E DE CIÊNCIA DE ESTUDANTES E PROFESSORES DE CIÊNCIAS}

Compreender a concepção do cientista e de Ciência de estudantes e professores da educação básica foi (e vem sendo) alvo de pesquisas constantes (Lederman, 1992; 2007). Embora definir o que seja a Ciência não se pareça uma tarefa trivial e nem muito menos goze de consenso entre pesquisadores da área, acessar a compreensão que estudantes e professores, de diferentes níveis de escolaridade, possuem foi (e ainda é) um interessante ponto de partida para a construção de estratégias didáticas que visam discutir conteúdos metacientíficos com estudantes da educação básica.

Por exemplo, Silva (2010), em um estudo com estudantes do ensino médio, apresenta que a concepção do cientista e de Ciência dos alunos investigados aproxima-se de concepções empírico-indutivistas e, principalmente em relação ao cientista, elas são estereotipadas e 
Caderno de Pesquisa em Ensino

de Ciências e Matemática

bastante conhecidas, como, por exemplo, homem, sem vida social, infalível e com único ambiente de trabalho o laboratório repleto de vidrarias e experimentos incompreensíveis. No que diz respeito ao que seria a Ciência, os participam aproximam o conceito de Ciência às práticas do biólogo.

Santos e Silva (2013), em um estudo com futuros professores de Física, alunos de diferentes semestres de instituição pública de ensino, apresentam resultado bastante similares aos encontrados por Silva (2010), ou seja, na qual a concepção atribuída ao cientista e ao seu local de trabalho também configura-se nos laboratórios, sendo sua aparência física peculiar ao que a mídia, geralmente, transmite, com destaque para as de perfil de loucura. Os autores também trazem outros resultados, como, por exemplo, a crença que a função social do cientista é sempre procurar benefícios para a sociedade, a partir de suas pesquisas.

Silva et al (2017), em um estudo com estudantes do ensino fundamental, relatam que a concepção de ciência dos alunos se ancorava em visões empiristas, indutivistas e dogmáticas sobre a ciência, próximas as já detalhadas por Silva (2010).

Reis e Galvão (2006), com base no estudo de enredo de histórias de ficção científica sobre o trabalho de um grupo de cientistas, produzidas por estudantes portugueses, notaram a falta de conhecimentos processuais e epistemológicos sobre a ciência, bem como a existência de diversas concepções estereotipadas e deturpadas sobre as características e o trabalho dos cientistas. Faria et al (2014) também usam uma atividade de escrita e discussão de histórias imaginadas sobre cientistas para a exploração das ideias dos alunos sobre a atividade científica, achando resultados similares.

Diante de estudos com grupos tão diversos, uma questão salta aos olhos, a saber: por que a mesma concepção do cientista e da Ciência é encontrada em diferentes grupos, com diferentes graus de escolaridade e diferentes experiências educacionais?

Uma possível resposta pode ser dada com base no estudo de Reznic, Massarani e Moreira (2019) que estudaram as representações do cientista e da Ciência em filmes de curtametragem exibidos no Festival Anima Mundi de 1993 a 2013. Os pesquisadores relatam que dos 102 filmes selecionados para a análise, foi notado que $80 \%$ dos curtas aparecem cientistas, em boa parte homens, sendo eles brancos e adultos, de jaleco/uniforme e em laboratórios secretos.

Embora não seja a finalidade deste trabalho aprofundar a questão, ela motiva a pesquisa que foi desenvolvida e relatada aqui. Como destaca Martins (2015), no que diz respeito ao

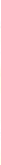


Caderno de Pesquisa em Ensino

de Ciências e Matemática

campo da Natureza da Ciência $(\mathrm{NdC})$ e seu ensino, um conjunto de questões vem motivando as pesquisas da área, são elas: o que ensinar sobre a $\mathrm{NdC}$ ? Por que ensinar sobre a $\mathrm{NdC}$ ? Como ensinar sobre a $\mathrm{NdC}$ ?

No presente trabalho, gostaríamos de levantar uma quarta questão às propostas por Martins (2015), seria ela: Como os professores mobilizam seus conhecimentos quando ensinam temas sobre a $N d C$ ? Voltaremos a esta questão no próximo tópico.

Das três questões propostas por Martins (2015), a que gera mais controvérsias e pesquisas na literatura é a última. Contudo, é possível encontrar alguns trabalhos que tratam da temática do cientista e da Ciência na educação básica.

Por exemplo, Ribeiro e Silva (2018) usam a História da Ciência, dentro do conteúdo de sistema circulatório, para produção de uma intervenção pedagógica com 22 alunos, visando à reconstrução da imagem do cientista do grupo.

Silva et al (2017) desenvolvem uma estratégia didática, para alunos do ensino fundamental, baseada, inicialmente no acesso às concepções do cientista e do seu local de trabalho, passando pelo uso de vídeos e de um texto paradidático para reconstrução das concepções estereotipadas encontradas na pesquisa.

Silva e Calaça (2017) elaboram um jogo didático, atrelado a um vídeo, para desmistificar a concepção estereotipada do cientista encontrada em alunos do ensino fundamental. No artigo, os pesquisadores sugerem que a utilização de atividades lúdicas, reflexivas e interativas como, por exemplo, o jogo didático e o uso de vídeos potencializam o ensino de conteúdos sobre a $\mathrm{NdC}$.

No próximo tópico, faremos uma discussão sobre a noção de conhecimento pedagógico do conteúdo referente ao tema Natureza da Ciência.

\section{A NOÇÃO DE CONHECIMENTO PEDAGÓGICO DO CONTEÚDO REFERENTE AO TEMA NATUREZA DA CIÊNCIA (PCK/NDC)}

No tópico anterior, propomos a inserção de mais questão, além das 3 anteriormente propostas por Martins (2015), seria ela: Como os professores mobilizam seus conhecimentos pedagógicos do conteúdo quando ensinam temas sobre a NdC? Contudo, antes disso, cabe-nos responder o que seria o $\mathrm{PCK} / \mathrm{NdC}$ e como ele é investigado na literatura.

Com base na noção de PCK de Shulman, alguns pesquisadores tentam responder a esta questão com suas investigações. Por exemplo, Schwartz e Lederman (2002), com base em

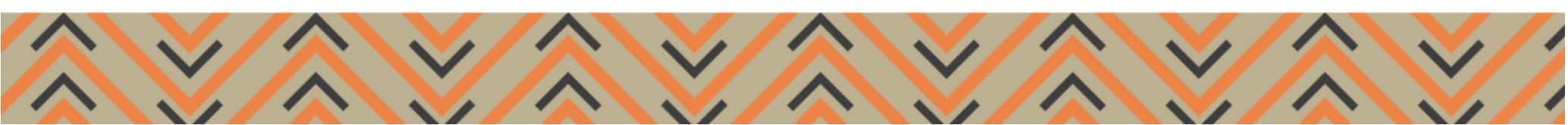


questionários e entrevistas, dizem que a compreensão dos conteúdos metacientíficos ${ }^{2}$ e suas conexões com outros conhecimentos da base de ensino do professor afetam as relações de ensino-aprendizagem. Para eles, os conhecimentos pedagógicos, metacientíficos e da Ciência se misturam para formar o $\mathrm{PCK} / \mathrm{NdC}$.

Silva e Martins (2019), com um estudo com futuros professores de Física, no qual foi utilizado uma ampla gama de ferramentas metodológicas, com destaque para o questionário intitulado Representação de Conteúdo, proposto por Loughran, Mulhall e Berry (2004), que se configura como uma ótima ferramenta para acessar indícios da mobilização do PCK, notaram que a complexidade e o ineditismo destas temáticas nos cursos de formação de professores de Física apresentou-se como um fator que dificultou a produção de estratégias didáticas para o ensino de aspectos da $\mathrm{NdC}$.

Outras investigações, que não trabalharam com o PCK, já destacaram esse mesmo problema. Por exemplo, Martins (2007), Pereira e Martins (2011) e Silva (2014) relatam que a pouca discussão sobre as relações entre a História e a Filosofia da Ciência nos cursos de formação inicial é um fator que implicar a dificuldade relatada por professores em trabalhar tais temáticas em sala de aula.

Retornando a questão, que motivou esse tópico. Da mesma forma que, principalmente após a definição do que seria o PCK por Shulman, vários outros pesquisadores buscaram conceituar o constructo, o mesmo, podemos assim dizer, aconteceu para o $\mathrm{PCK} / \mathrm{NdC}^{3}$.

Por exemplo, Para Abd-El-Khalick, Bell e Lederman (1998), o PCK/NdC configura-se como o conjunto de conhecimentos e suas representações didáticas que fundamentam a aprendizagem de aspectos da $\mathrm{NdC}$ pelos estudantes.

Silva e Martins (2019) ressaltam que o PCK/NdC surge da transformação de diferentes conhecimentos da base para o ensino de conteúdos metacientíficos que o professor possui. Sendo possível o desenvolvimento destes conhecimentos da base, inclusive o PCK/NdC, a partir da reflexão de experiências formativas que os futuros professores de Física participam nos cursos de formação. Dando ao PCK/NdC uma característica evolutiva e não estática.

Ainda, em Silva e Martins (2019), os pesquisadores apresentam alguns modelos de PCK/NdC, para professores de Ciências, encontrados na literatura. Apresentando, inclusive,

\footnotetext{
${ }^{2}$ Uma explicação mais aprofundada do termo conteúdos metacientíficos será apresentada em Silva e Martins (2018).

${ }^{3}$ Os modelos de PCK/NdC - (Hanuscin, Lee e Akerson (2010); Demirdogen e Uzuntiryaki-Kondakçl (2016) e de nossa própria autoria - são amplamente discutidos em Silva e Martins (2019). Para maiores esclarecimentos, sugerimos uma consultada ao trabalho citado.
} 
Caderno de Pesquisa em Ensino

de Ciências e Matemática

uma proposta para tal finalidade. Acreditamos que estes modelos podem nos dar indícios para respondermos a questão deste tópico.

Segundo os autores, a necessidade de um modelo próprio surgiu devido à proposta de Demirdogen e Uzuntiryaki-Kondakçl (2016), cf. figura 2, os componentes da proposta não são conectados, passando a impressão que os conhecimentos da base dos professores não se dialogam no processo de desenvolvimento do PCK/NdC.

Figura 2 - Proposta de PCK/NdC de futuros professores de Química

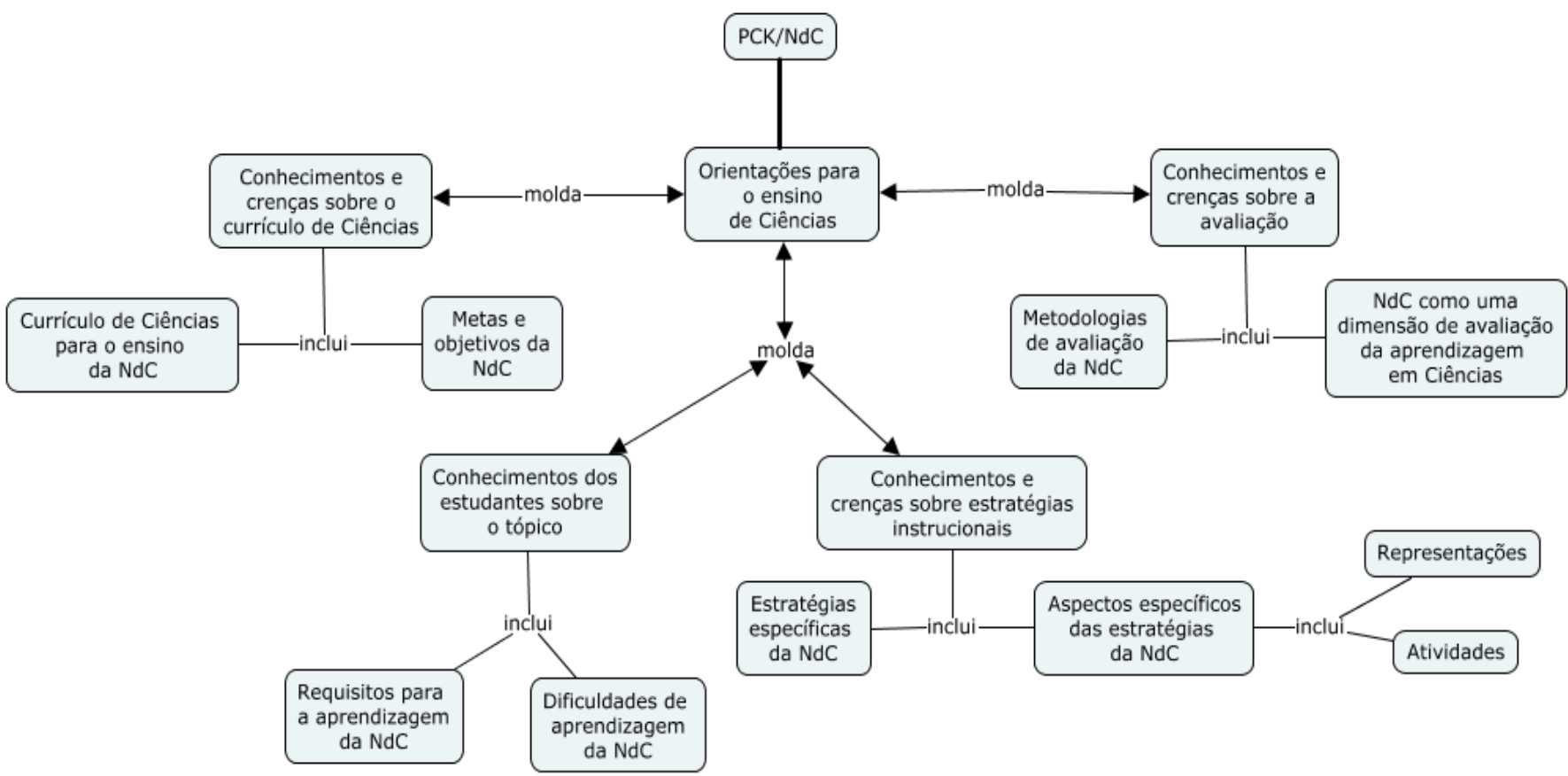

Fonte: [Silva e Martins, 2019, p740.]

Já, em Hanuscin, Lee e Akerson (2010), os pesquisadores relatam, que na proposta das autoras, a exclusão de fatores não cognitivos, como, por exemplo, as crenças dos professores, a afetividade e outros conhecimentos subjetivos, como podemos notar na figura 3 , motivou uma nova proposta. 
Figura 3 - Proposta de PCK/NdC de professores de Ciências

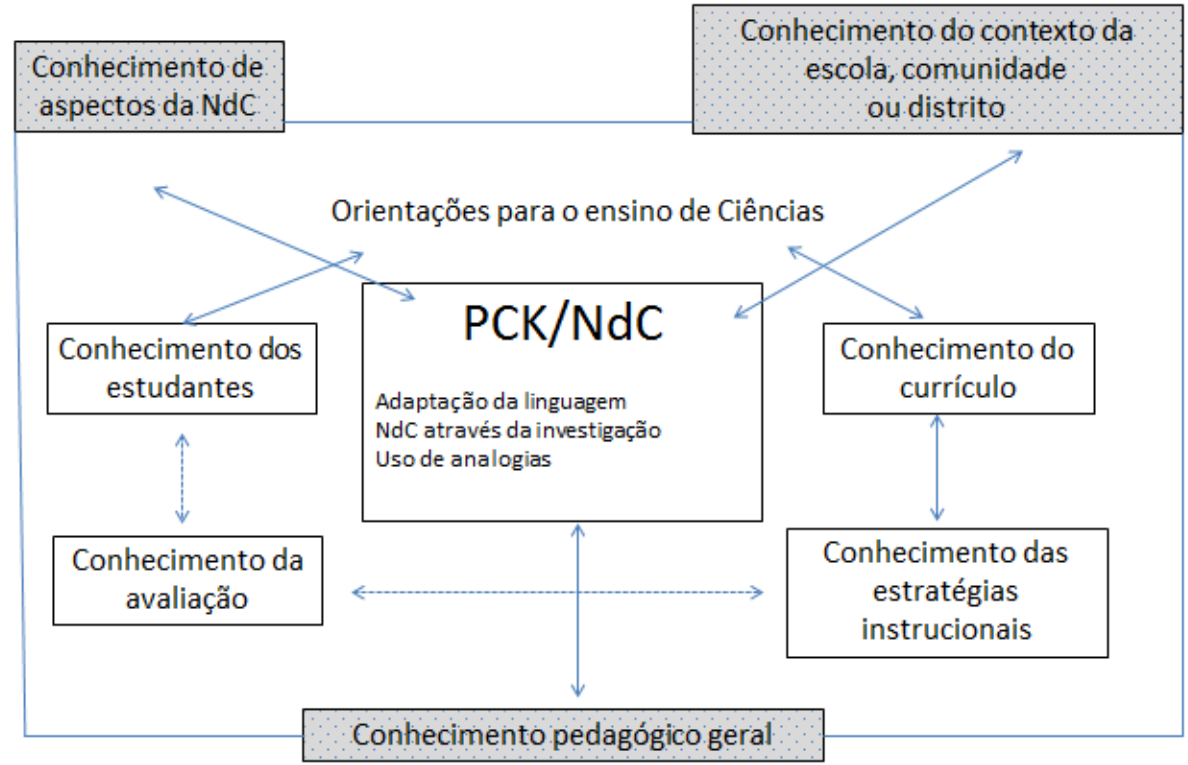

Fonte: [Silva e Martins, 2019, p740.]

Por fim, Silva e Martins (2019) apresentam o seu modelo de PCK/NdC, como podemos notar na figura 4.

Figura 4. Proposta de PCK/NdC de futuros professores de Física

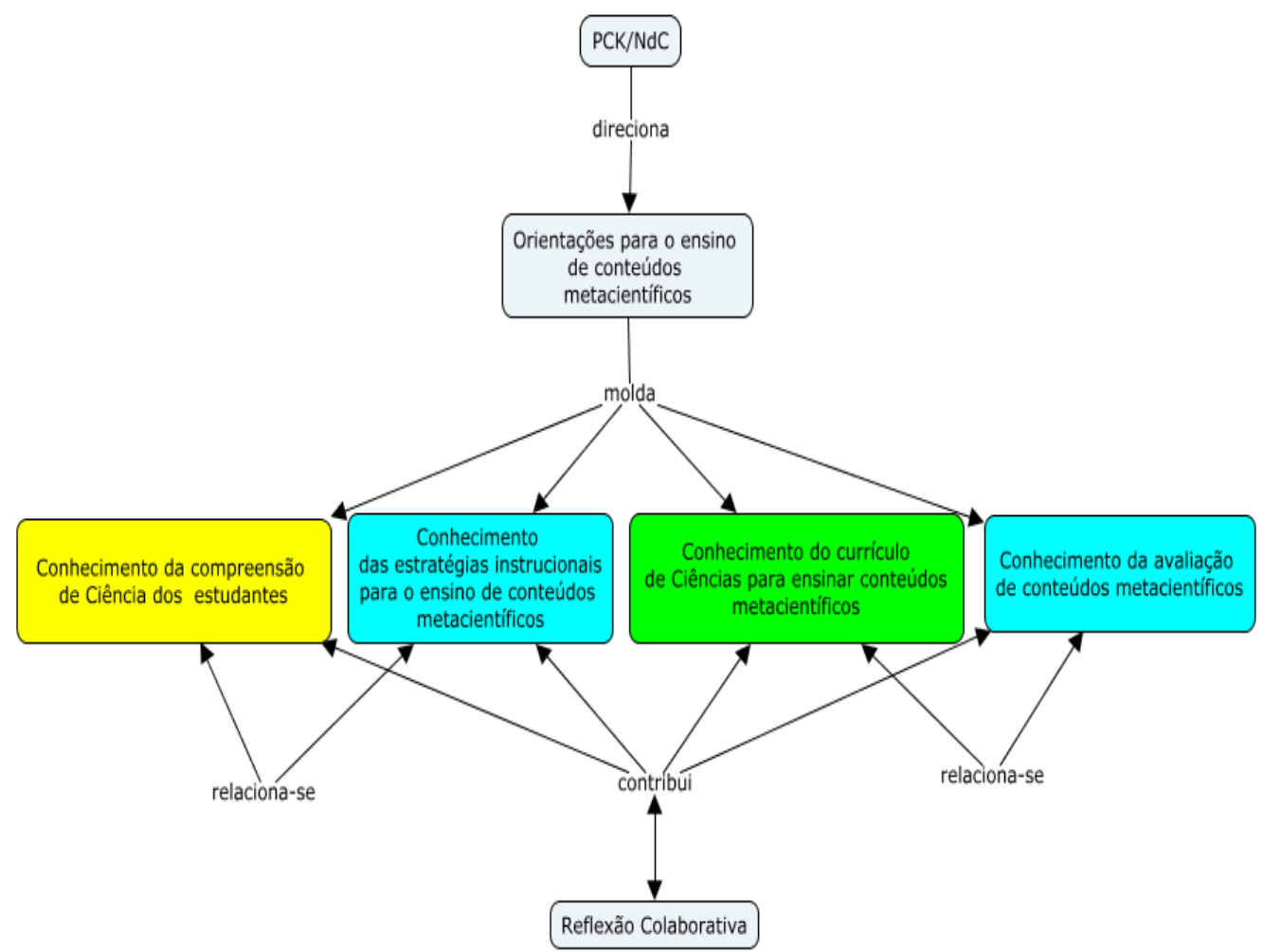

Fonte: [Silva e Martins, 2019, p740.] 
No quadro 1, extraído do trabalho dos autores, é possível ver a caracterização de cada componente do PCK/NdC.

Quadro 1 - Conhecimentos do PCK/NdC, segundo Silva e Martins (2018).

\begin{tabular}{|c|c|}
\hline Conhecimento relacionado ao $\mathrm{PCK} / \mathrm{NdC}$ & Descrição sucinta \\
\hline $\begin{array}{l}\text { Conhecimento da compreensão de Ciência dos } \\
\text { estudantes da Educação Básica }\end{array}$ & $\begin{array}{l}\text { Configuram-se como os conhecimentos dos professores } \\
\text { sobre a compreensão dos estudantes sobre a Ciência, } \\
\text { conhecimentos prévios e dificuldades de aprendizagem } \\
\text { relacionadas aos conhecimentos metacientíficos. }\end{array}$ \\
\hline $\begin{array}{l}\text { Conhecimento das estratégias instrucionais para o } \\
\text { ensino de conteúdos metacientíficos }\end{array}$ & $\begin{array}{l}\text { Diz respeito ao conhecimento de estratégias didáticas } \\
\text { relacionadas aos conhecimentos metacientíficos, } \\
\text { principalmente suas potencialidades e dificuldades de } \\
\text { inserção. }\end{array}$ \\
\hline $\begin{array}{l}\text { Conhecimento do currículo de Ciências para ensinar } \\
\text { conteúdos metacientíficos }\end{array}$ & $\begin{array}{l}\text { Este componente compreende o conhecimento que os } \\
\text { professores necessitam possuir sobre as metas e objetivos } \\
\text { de aprendizagens dos alunos em relação aos conhecimentos } \\
\text { metacientíficos que desejam lecionar. }\end{array}$ \\
\hline $\begin{array}{l}\text { Conhecimento da avaliação de conteúdos } \\
\text { metacientíficos }\end{array}$ & $\begin{array}{l}\text { Ele constitui-se como os elementos de metodologias de } \\
\text { avaliação das aprendizagens de conhecimentos } \\
\text { metacientíficos, que são aprendidos e vivenciados pelos } \\
\text { futuros professores de Física na sua formação inicial. Nele, } \\
\text { ele encontra exemplos e orientações de propostas de } \\
\text { avaliação específicas para a situação, decorrentes, } \\
\text { principalmente de experiências formativas. }\end{array}$ \\
\hline
\end{tabular}

Fonte: [Extraído de Silva e Martins, 2019]

Outro elemento interessante da proposta dos autores é intitulada de Reflexão Colaborativa $^{4}$. Para os pesquisadores, ela possibilita o desenvolvimento do PCK/NdC dos professores de Ciências, principalmente quando eles são expostos diante de dilemas e situações problemáticas de ensino-aprendizagem, exigindo-lhes uma tomada de decisão no sentido de resolver o problema detectado. É nesse ponto, conforme os investigadores, que os professores mobilizam os seus conhecimentos subjetivos, como, por exemplo, crenças didáticopedagógicas e, também, percebem deficiências nos seus conhecimentos que estruturam a base para o ensino, como os conteúdos metacientíficos, os conhecimentos relacionados aos processos de avaliação e construção de estratégias didáticas, dentre outros.

No próximo tópico, apresentamos o desenho metodológico do estudo.

\footnotetext{
${ }^{4}$ A noção de reflexão colaborativa e seu papel dentro do PCK/NdC é discutida em Silva e Martins (2018). Sugerimos a leitura do artigo para maiores aprofundamentos.
} 
Caderno de Pesquisa em Ensino

de Ciências e Matemática

\section{DESENHO METODOLÓGICO DO ESTUDO}

No estudo, que apresentamos, buscamos, como pano de fundo, elementos que possam responder ao questionamento feito "Como os professores mobilizam seus conhecimentos quando ensinam temas sobre a $N d C$ ”. De forma mais específica, enfatizamos os conhecimentos mobilizados na produção de atividades com tal finalidade, em particular, nas sequências didáticas.

A pesquisa se enquadra como qualitativa, pois segundo Marconi (2003) e Moreira (2011), o investigador encontra-se imerso no local pesquisado, os dados coletados são descritivos e existe a preocupação com o processo desenvolvido e não, somente, com o produto. Também, segundo Moreira (2011) ela se encaixa como interpretativa, pois:

[...] interpretação dos significados atribuídos pelos sujeitos às suas ações em uma realidade socialmente construída, através de observação participativa, isto é, o pesquisador fica imerso no fenômeno de interesse. Os dados obtidos por meio dessa participação são de natureza qualitativa e analisados de forma correspondente (MOREIRA, 2011, p.76).

A investigação foi desenvolvida com uma futura professora de Ciências, estudante de um curso de licenciatura em Ciências da Natureza, de uma instituição pública brasileira. Ela cursava, no momento da investigação, os três últimos períodos do curso e era residente do Programa Residência Pedagógica do mesmo curso.

A atividade de construção da sequência didática (Anexo A) foi solicitada e desenvolvida dentro da disciplina de História e Filosofia da Ciência no ensino de Ciências, no semestre de 2018.2, na qual a participante frequentava. A disciplina tinha por característica discutir elementos da Epistemologia da Ciência, usando autores com Karl Popper, Thomas Kuhn, Paul Feyerabend e Gaston Bachelard, bem como um estudo sobre a Natureza da Ciência e as suas relações com o ensino-aprendizagem. Como elemento avaliativo, foi solicitada a produção de uma sequência didática com a finalidade de discutir, no ensino fundamental, a concepção do Cientista e do ambiente de trabalho e como a Ciência é construída.

Dessa forma, o objetivo dessa investigação reside na compreensão de como uma futura professora de Ciências da Natureza mobiliza o seu PCK sobre o cientista e a Ciência, ao construir uma sequência didática, com finalidades de ensinar temas sobre a Ciência no ensino fundamental. 
Como instrumentos de coleta de dados usamos a própria sequência didática (SD) da estudante, cedida pela mesma para investigação, como também o questionário Representação de Conteúdo (CoRe), encontrado no Anexo B.

Por fim, para analisar os dados, usamos como categorias os conhecimentos que fazem parte do PCK/NdC propostos por Silva e Martins (2018; 2019), que são: Conhecimento da compreensão de Ciência dos estudantes da Educação Básica, conhecimento das estratégias instrucionais para o ensino de conteúdos metacientíficos, conhecimentos do currículo de Ciências para ensinar conteúdos metacientíficos e conhecimentos da avaliação de conteúdos metacientíficos. No próximo tópico, apresentamos, em si, a análise que buscou investigar indícios da mobilização do PCK/NDC na produção de sequências didáticas.

\section{ANÁLISE DOS DADOS: INDÍCIOS DA MOBILIZAÇÃO DO PCK/NDC NA SEQUÊNCIA DIDÁTICA}

Para analisar os dados, usamos como categorias os conhecimentos que fazem parte do PCK/NdC propostos por Silva e Martins (2018; 2019), conforme destaca acima. Começaremos pelo Conhecimento da compreensão de Ciência dos estudantes da educação básica.

\section{A influência do Conhecimento da compreensão de Ciência dos estudantes da educação básica na mobilização do PCK/NdC}

Conforme destacam Silva e Martins (2019), esse conhecimento perpassa pela compreensão de concepções prévias, dificuldades de aprendizagem e crenças sobre as possibilidades dos seus estudantes de aprenderem ou não sobre o conteúdo a ser discutido. Notamos na SD alguns elementos que indicam a presença desse conhecimento, observe:

Figura 5 - Excerto do desenvolvimento metodológico da SD

Desenvolvimento metodológico:

$1^{\mathrm{a}}$ Aula: $1^{\circ}$ Questionário: Como a Ciência é construída.

Aplicação de questionário sobre as concepções alternativas sobre ciência, com foco na visão do que é ciência para os alunos.

$2^{\circ}$ Questionário: O que é necessário para elaborar princípios ou leis científicas?

Aplicação do questionário sobre as concepções alternativas dos alunos sobre como o que é necessário para se formular uma teoria. Neste questionário, as respostas serão ditas pelos alunos em voz alta e discutidas.

Fonte: [Recorte da SD da participante]

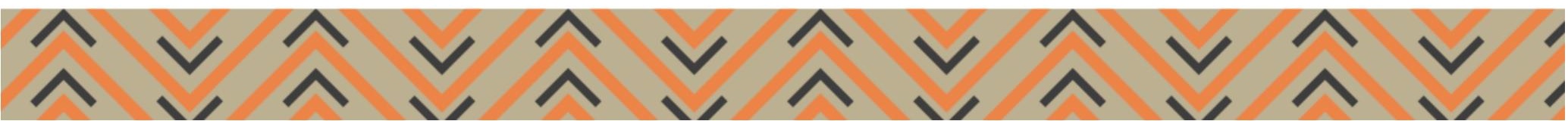


Na figura 5, notamos que a participante tem a preocupação de iniciar a sua SD com um questionário para acessar as concepções dos estudantes sobre a Ciência, mostrando indícios da mobilização do conhecimento da compreensão de Ciência dos estudantes da educação básica. Conforme já destacado em tópicos anteriores, desse artigo, os estudantes do ensino fundamental demonstram concepções empírico-indutivas sobre a Ciência. Em outros momentos da SD também é possível observar a mobilização desse elemento do $\mathrm{PCK} / \mathrm{NdC}$, como, por exemplo, no texto paradidático produzido para a quarta aula. Podemos observar, na figura 6 , que a futura professora é ciente das existências dessas concepções e elas aparecem na sua produção.

Figura 6 - Excerto do texto didático da SD

$4^{\circ}$ Aula: Leitura do texto.

Etapa I: Leitura de texto didático sobre a visão da imagem do cientista.

O cientista é apenas um homem velho?

Durante uma aula em uma turma do ensino fundamental, o professor de ciências tentava explicar para os alunos sobre as Leis de Newton, porém, com toda a bagunça e desinteresse dos alunos, a aula se tornava impossível.

O professor, que escrevia no quadro e pedia por silêncio, já não suportava mais todo aquele alvoroço. Apagou o quadro, sem nem ter terminado, causando espanto nos alunos e criando uma onda de silêncio. Enquanto os alunos se entreolhavam, o professor retirava um projetor da mochila e logo o ligou na tomada.

-Eitaa! - disse um aluno chamado Pedro, ao ver a foto de um homem estranho com os cabelos assanhados.

-Newton - disse o professor - foi ele quem criou estas leis no qual eu venho tentando explicar.

- Professor, porque ele é estranho? - indagou João, outro aluno que estava muito curioso.

- Porque ele é um cientista! - respondeu Bruna, a aluna mais levada da sala.

-Nada disso! - disse o professor - ele não é estranho pelo fato de ser cientista, essa não é uma característica que define o cientista, Bruna.

Fonte: [Recorte da SD da participante]

Notamos que a participante, no seu texto paradidático, preocupa-se em desmistificar a possível presença de concepções estereotipadas do cientista nos seus estudantes, o que denota a mobilização do respectivo conhecimento no seu PCK/NdC.

Nas questões 1, 5 e 6 do CoRe também é possível perceber que a futura professora detém preocupações em trabalhar as dificuldades de melhores compreensões das concepções do cientista e da Ciência, observe:

Pretende-se que seja desmistificada a visão do cientista como um gênio que trabalha sozinho e é anti social. A proposta é aproximar os alunos à realidade de um cientista e instigar o trabalho em grupo, ou trabalho coletivo. Para isso, um questionário servirá como norte do desenvolvimento das aulas, em que será trabalhado mais a fundo o que eles possuem mais dificuldade (CoRe, questão 1, grifo nosso). 
Um fator que dificulta muito a aprendizagem desses alunos com relação à imagem equivocada do cientista, é por exemplo, abrir o livro didático e perceber alguns erros conceituais que incentivam ao aluno a continuar na crença de que o cientista é alguém extremamente inteligente e diferente (CoRe, questão 5).

A forma como a própria escola muitas vezes trata a ciência, ou como a família entende a ciência, fazendo com que o aluno seja influenciado e pensar que a ciência não é para todos ou que precisa ter nascido gênio, para se trabalhar sozinho e ser um cientista (CoRe, questão 6).

No próximo tópico, iremos abordar a influência dos conhecimentos relacionados ao campo das estratégias didáticas na mobilização do PCK/NdC da futura professora.

\section{A influência do conhecimento das estratégias instrucionais para o ensino de conteúdos metacientíficos na mobilização do PCK/NdC}

Para Silva e Martins (2019), esse conhecimento diz respeito aos conhecimentos de estratégias didáticas relacionadas aos conhecimentos metacientíficos, principalmente suas potencialidades e dificuldades de inserção.

A futura professora apresenta um leque de atividades didáticas e todas elencadas entre si na sua proposta de $\mathrm{SD}$, como, por exemplo:

a) o uso do questionário, na aula 1, para acessar e desmitificar as concepções dos estudantes sobre o cientista e a Ciência.

b) o uso de um texto da revista Ciência Hoje das Crianças, solicitando a leitura e explicação de partes lidas. É interessante como ela trata da pós-leitura, mostrando uma relação para seus alunos entre as aulas que compõem a SD, observe:

Como o texto trata de forma mais aprofundada a profissão de um cientista naturalista, a proposta da segunda etapa é levar os alunos para alguma parte da escola que tenha plantas e insetos e perguntar a eles se o cientista pode trabalhar apenas com a observação. Depois cada aluno fará um texto sobre o que entendeu (Segunda etapa da aula 2, Recorte da SD).

c) uso de experimento em sala de aula, conforme pode ser visto na figura 7. 
Figura 7 - Aula sobre como funciona o trabalho do cientista

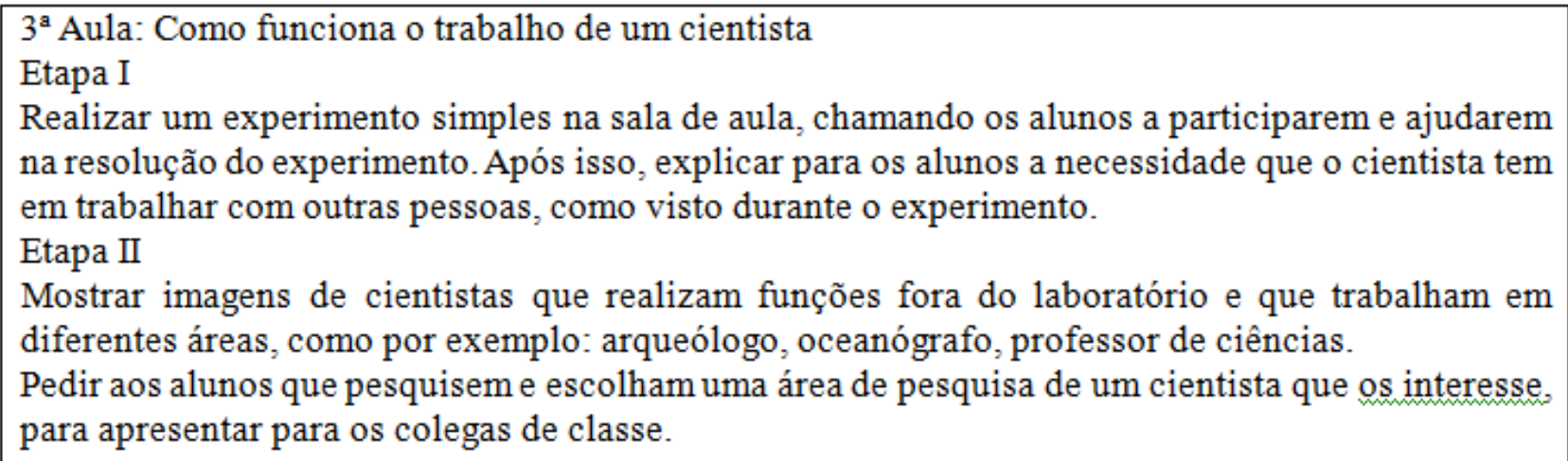

Fonte: [Recorte da SD da participante]

d) uso de texto didático para desmistificar a visão do cientista de autoria própria. O texto pode ser encontrado no Anexo B.

e) vídeo sobre a Madame Curie, discutindo o papel da mulher na Ciência.

Por fim, na questão 7 do CoRe, a futura professora enaltece a necessidade de pluralidade de atividade para tratar do tema, o que pode nos indicar que esse conhecimento do seu PCK/NdC foi bem desenvolvido no decorrer da sua formação inicial.

Não permitir que os alunos se percam durante a explicação, não permitir que percam o foco e sempre procurar outras formas de abordar um assunto, sem ser somente na sala de aula escrevendo no quadro. É necessário abordar problemas diferentes com estratégias diferentes (CoRe, questão 7).

No próximo tópico, iremos abordar a influência dos conhecimentos relacionados no campo curricular na mobilização do PCK/NdC participante.

\section{A influência do conhecimento currículo de Ciências para ensinar conteúdos metacientíficos na mobilização do PCK/NdC}

No trabalho de Silva e Martins (2019), eles descrevem este componente do PCK/NdC como o conhecimento que os professores necessitam possuir sobre as metas e objetivos de aprendizagens dos alunos em relação aos conhecimentos metacientíficos que desejam lecionar. Diz respeito à compreensão da relação dos objetivos e conteúdos e conhecimento de documentos oficiais da área, por exemplo.

Na SD participante podemos notar que os objetivos e conteúdos estão bem traçados para uma discussão sobre a concepção do cientista e coerente com a metodologia que foi idealizada 
Caderno de Pesquisa em Ensino de Ciências e Matemática

para tal finalidade, sendo coerente, inclusive, com a proposta de unidade didática nomeada, como observado na figura 8.

Figura 8 - Objetivos e conteúdos traçados na SD

\begin{tabular}{|c|c|c|c|}
\hline \multicolumn{4}{|c|}{ ESCOLA: EXCLUIDA } \\
\hline \multicolumn{4}{|c|}{ Professora: EXCLUÍDA } \\
\hline & $\begin{array}{l}\text { Turma: } \\
\text { 9ano }\end{array}$ & $\begin{array}{l}\text { Data: } \\
04 / 09 / 2019 \text { à } 16 / 10 / 2019\end{array}$ & $\begin{array}{l}\text { Duração: } \\
2 \text { horas por aula }\end{array}$ \\
\hline \multicolumn{4}{|c|}{ Unidade didática: A imagem equivocada do cientista, da ciência e de sua natureza. } \\
\hline \multicolumn{4}{|c|}{$\begin{array}{l}\text { Objetivos específicos: } \\
\text { Compreender como se constrói a Ciência } \\
\text { Compreender o trabalho do cientista } \\
\text { Identificar os diferentes trabalhos de um cientista } \\
\text { Compreender que o cientista trabalha com a ajuda de outros }\end{array}$} \\
\hline \multicolumn{4}{|c|}{ Conteúdos: } \\
\hline 1.0 & - Como a Ciência é cons & uída & \\
\hline 2.0 & -O trabalho de um cient & & \\
\hline 2.1 & - Como funciona o traba & o de um cientista & \\
\hline 2.2 & - As diferentes áreas de $\mathrm{t}$ & balho de um cientista & \\
\hline 2.3 & - O cientista e o trabalho & m conjunto & \\
\hline 2.4 & - O cientista é apenas um & lomem velho? A imagem do & a como intocável. \\
\hline 2.5 & - O papel da mulher na $\mathrm{c}$ & ncia. & \\
\hline
\end{tabular}

Fonte: [Recorte da SD da participante]

Percebemos que os objetivos da SD também são enaltecidos nas respostas das questões 1 e 2 do CoRe da futura professora, observe:

Pretende-se que seja desmistificada a visão do cientista como um gênio que trabalha sozinho e é anti social. A proposta é aproximar os alunos à realidade de um cientista e instigar o trabalho em grupo, ou trabalho coletivo. Para isso, um questionário servirá como norte do desenvolvimento das aulas, em que será trabalhado mais a fundo o que eles possuem mais dificuldade (CoRe, questão 1, grifo nosso).

Essa ideia é importante para que seja trabalhada a concepção de cientista que cada aluno tem, focando na desconstrução dessa concepção, caso esteja equivocada. É importante ser trabalhada na sala de aula para que a própria compreensão da ciência seja facilitada. Logo que, se a profissão de um cientista for entendida como difícil, a ciência também se tornará difícil de ser compreendida (CoRe, questão 2).

Neste ponto, parece-nos que a futura professora de Ciências relaciona os conhecimentos do currículo com os conhecimentos sobre a compreensão de Ciência dos seus alunos, a partir do momento que ela associa a aprendizagem da compreensão de Ciência (embasada nos conteúdos e objetivos da figura 8) estejam concatenados à própria compreensão de Ciência que

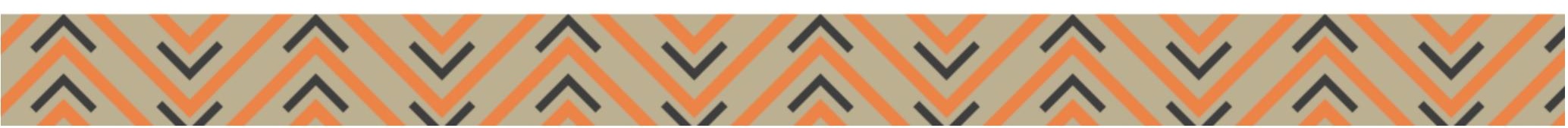


os estudantes do ensino fundamental apresentam, revelando que os componentes do PCK/NdC podem conectar-se, como prevê o modelo de Silva e Martins (2019), na figura 4.

No próximo tópico, teceremos as considerações sobre a influência dos conhecimentos da avaliação na mobilização do PCK/NdC.

\section{A influência do conhecimento da avaliação de conteúdos metacientíficos na mobilização do PCK/NdC}

Por fim, o último componente do PCK/NdC proposto no modelo de Silva e Martins (2019) diz respeito aos conhecimentos de propostas de avaliação do professor para averiguar a aprendizagem de conteúdos metacientíficos. Já na oitava questão do CoRe podemos notar as preocupações da futura docente em fazer uma avaliação que possa congregar mais alunos, no sentido de uma avaliação mais dinâmica, buscando, principalmente, o combate às visões estereotipadas do cientista, observe:

Aplicar questionários e fazer debates em círculos, para que todos se sintam a vontade e possam focar na ciência e no cientista como algo natural. Propor também aos alunos a trabalharem em equipe, seja no laboratório, seja na sala de aula ou durante pesquisas em grupo. Aproximando sempre a ciência ao aluno e o avaliando a todo momento, para que quando ocorra um equívoco por parte do aluno, seja planejada uma nova dinâmica para resolvê-lo (CoRe, questão 8).

Esta mesma preocupação é notada nas avaliações que a participante elabora para cada aula, conforme pode ser visto nas figuras 9, 10, 11 .

Figura 9 - Proposta de avaliação para a aula 2

$2^{\text {a }}$ Aula: O trabalho de um cientista

Etapa I

Aplicar texto base da Edição 264 "Como ser Cientista", da revista Ciência Hoje das Crianças, pedir que cada aluno leia uma parte e explique em uma simples frase o que entendeu com a parte lida.

Etapa II

Como o texto trata de forma mais aprofundada a profissão de um cientista naturalista, a proposta da segunda etapa é levar os alunos para alguma parte da escola que tenha plantas e insetos e perguntar a eles se o cientista pode trabalhar apenas com a observação.

Depois cada aluno fará um texto sobre o que entendeu.

Fonte: [SD da participante, grifo nosso] 
Figura 10 - Proposta de avaliação para a aula 3

$3^{\text {a }}$ Aula: Como funciona o trabalho de um cientista

Etapa I

Realizar um experimento simples na sala de aula, chamando os alunos a participarem e ajudarem na resolução do experimento. Após isso, explicar para os alunos a necessidade que o cientista tem em trabalhar com outras pessoas, como visto durante o experimento.

Etapa II

Mostrar imagens de cientistas que realizam funções fora do laboratório e que trabalham em diferentes áreas, como por exemplo: arqueólogo, oceanógrafo, professor de ciências.

Pedir aos alunos que pesquisem e escolham uma área de pesquisa de um cientista que os interesse, para apresentar para os colegas de classe.

Fonte: [SD da participante, grifo nosso]

Figura 11 - Proposta de avaliação para a aula 4 e 5

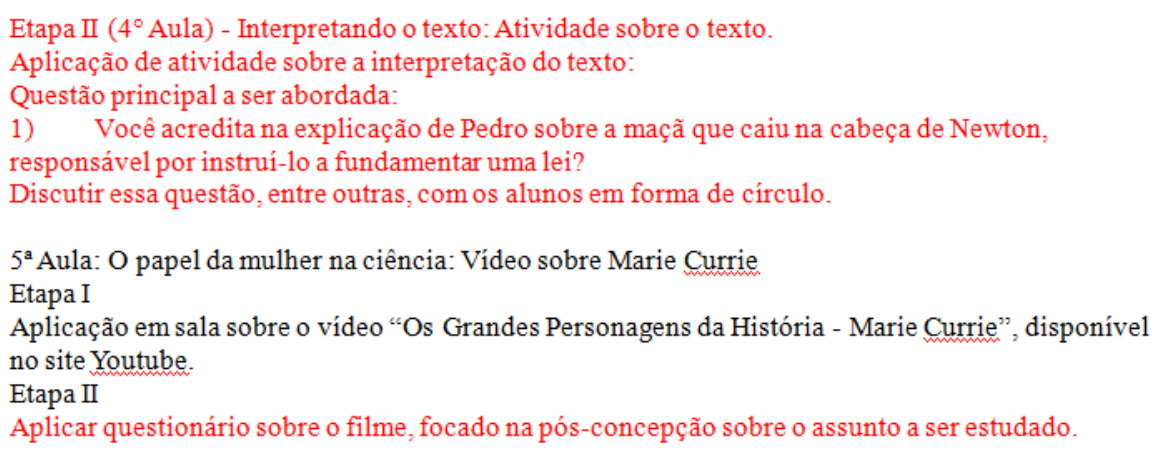

Fonte: [SD da participante, grifo nosso]

Podemos perceber que existe uma preocupação da avaliação da futura professora ser conectada com os objetivos e conteúdos da SD, principalmente na desmistificação da concepção estereotipada do cientista, o que denota possíveis conexões entre os conhecimentos do currículo e de avaliação, como já destacam Silva e Martins (2018; 2019) nas suas investigações anteriores.

Por fim, com base na proposta de imagem do PCK de Silva (2018), apresentamos como seria uma fotografia do PCK/NdC da participante após a análise de sua SD. Queremos salientar que concordamos com Silva (2018) que o PCK não é estático e nem muito menos o PCK/NdC. $\mathrm{O}$ autor defender que ele é volátil e conforme descreve pode ser desenvolvido a partir da reflexão colaborativa, principalmente quando o docente é exposto a situações que colocam em cheque-mate seus conhecimentos, crenças e convicções. Entretanto, defendemos que uma primeira imagem do PCK/NdC pode ser um indicativo interessante aos docentes dos cursos de formação de professores das deficiências e qualidades do PCK/NdC de seus estudantes. A figura 12 representa o $\mathrm{PCK} / \mathrm{NdC}$ da futura professora. 
Figura 12 - Primeira imagem do PCK/NdC da participante

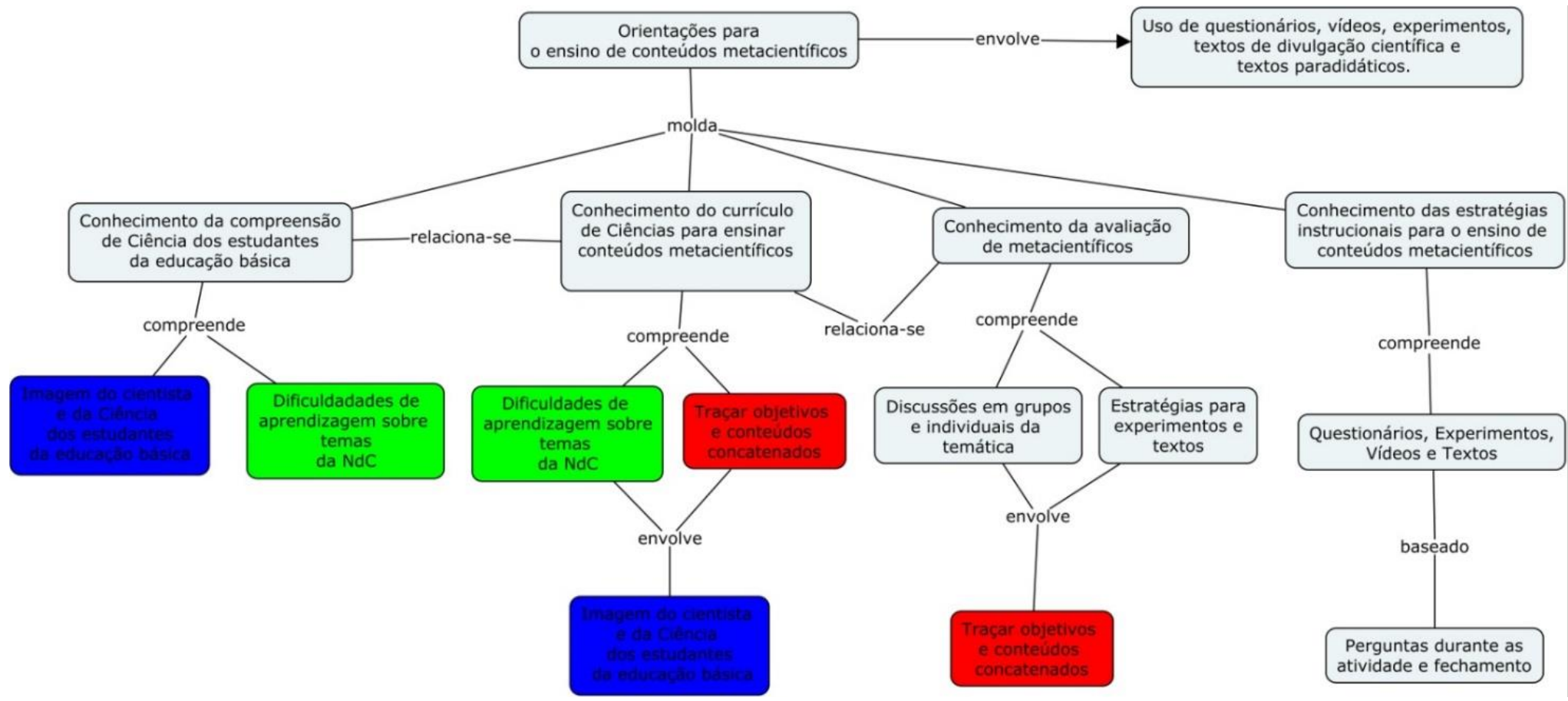

Fonte: [SD da participante. Elaborada no CmapTools 6.04]

No próximo tópico, tecemos nossas conclusões sobre o estudo.

\section{CONCLUSÕES DO ESTUDO}

. Neste trabalho, que relata um estudo desenvolvido com uma futura professora de Ciências, buscamos evidenciar indícios da mobilização do PCK/NdC, em especial relacionado com a concepção de Ciência e do cientista, tomando como base a construção de uma SD para discussão de temas sobre a $\mathrm{NdC}$, com estudantes do ensino fundamental.

Inicialmente, notamos que a produção de sequências didáticas podem colaborar no acesso de indícios da mobilização do PCK de futuros professores, de modo geral, e no $\mathrm{PCK} / \mathrm{NdC}$, de forma específica, como destacado no trabalho.

Segundo, evidenciamos que no processo de construção da SD, os diferentes conhecimentos que compõem o $\mathrm{PCK} / \mathrm{NdC}$ estão em constante diálogo, entre si, como já evidenciado na pesquisa de Silva e Martins (2019). No nosso caso, ficaram latentes as confluências entre conhecimentos relacionados ao currículo, à compreensão de Ciência dos estudantes e à avaliação. Elas também podem ser observadas nas respostas dadas ao CoRe. 
Caderno de Pesquisa em Ensino

de Ciências e Matemática

Assim, acreditamos que a produção de SD apresenta um potencial interessante para a detecção de indícios do PCK/NdC, dando respostas aos docentes formadores das deficiências e qualidades dos conhecimentos da base para o ensino de temas sobre a $\mathrm{NdC}$ dos futuros professores, principalmente quando desenvolvem estratégias didáticas, como, por exemplo as SD, para ensinar conteúdos metacientíficos.

Entendemos que um rico desdobramento desde trabalho seria a aplicação da SD produzida na educação básica e uma posterior análise das diferenças ocasionadas no PCK/NdC da futura professora, tomando como ponto de investigação estas novas vivências. Compreendemos que seja o próximo passo e um desdobramento natural dessa pesquisa, que será relatado em trabalhos futuros.

Por fim, acreditamos também que a produção de SD, atrelada a sua interpretação com base na proposta de Silva e Martins (2018; 2019), podem apresentar algumas respostas para a questão formulada "Como os professores mobilizam seus conhecimentos quando ensinam temas sobre a $N d C$ ? ", como observado no estudo, servindo como suporte para a elaboração de atividades que potencializem o PCK/NdC de futuros professores de Ciências.

\section{AGRADECIMENTOS}

$\mathrm{O}$ autor do trabalho agradece, enormemente, à discente do curso de licenciatura em Ciências da Natureza da UFPI pela liberação da sua sequência didática, elaborada na disciplina de História e Filosofia da Ciência no ensino de Ciências, para fins de estudo.

\section{REFERÊNCIAS}

ABD- EL- KHALICK, F.; BELL, R. L.; LEDERMAN, N. G. The nature of science and instructional practice: Making the unnatural natural. Science Education, v.82, n.4, p.417-436, 1998.

BOLÍVAR, A. Conocimiento didáctico del contenido y didácticas específicas. Profesorado. Revista de currículum y formación del profesorado, v.9, n.2, p.1-25, 2005.

DEMIRDOGEN, B.; UZUNTIRYAKI-KONDAKÇI, E. Closing the gap between beliefs and practice: Change of pre-service chemistry teachers' orientations during a PCK-based NOS course. Chemistry Education Research and Practice, v.1, n.4, p.818-841, 2016.

FARIA, C.; FREIRE, S.; GALVÃO, C.; REIS, P.; FIGUEIREDO, O. "Como trabalham os cientistas?" Potencialidades de uma atividade de escrita para a discussão acerca da natureza da ciência nas aulas de ciências. Ciência \& Educação (Bauru), v.20, n.1, p.1-22, 2014.

GROSSMAN, P. L. The making of a teacher: Teacher knowledge and teacher education. Teachers College Press, Teachers College, Columbia University, 1990.

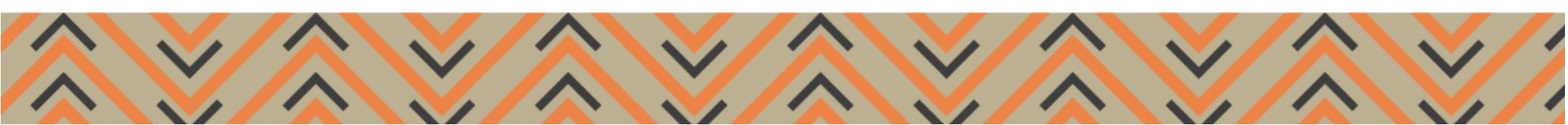


HANUSCIN, D. L.; LEE, M. H.; AKERSON, V. L. Elementary teachers' pedagogical content knowledge for teaching the nature of science. Science Teacher Education, v.95, n.1, p.145$167,2010$.

KIND, V. Pedagogical content knowledge in science education: perspectives and potential for progress. Studies in science education, v.45, n.2, p.169-204, 2009.

LEDERMAN, N. G. Students' and teachers' conceptions of the nature of science: A review of the research. Journal of research in science teaching, v.29, n.4, p.331-359, 1992.

LEDERMAN, N. G. Nature of science: Past, present, and future. In: ABELL, S.K (ORG); LEDERMAN, N.G (Org). Handbook of research on science education, p. 845-894, 2007.

LOUGHRAN, J.; MULHALL, P.; BERRY, A. In search of pedagogical content knowledge in science: Developing ways of articulating and documenting professional practice. Journal of research in science teaching, v.41, n.4, p.370-391, 2004.

MAGNUSSON, S.; KRAJCIK, J.; BORKO, H. Nature, sources, and development of pedagogical content knowledge for science teaching. In: Examining pedagogical content knowledge, p. 95-132, 1999.

MARCONI, M. D. A. (2003). Fundamentos de metodologia científica, São Paulo: Atlas, 2003.

MARTINS, A. F. P. (2007). História e Filosofia da Ciência no ensino: Há muitas pedras nesse caminho... Caderno Brasileiro de Ensino de Física, v.24, n.1, p.112-131, 2007.

MARTINS, A. F. P. Natureza da Ciência no ensino de ciências: uma proposta baseada em "temas" e "questões". Caderno Brasileiro de Ensino de Física, v.32, n.3, p.703-737, 2015.

MOREIRA, M. A. Metodologia de Pesquisa em Ensino. São Paulo: Livraria da Física, 2011.

PEREIRA, G. J. S. A.; MARTINS, A. F. P. A inserção de disciplinas de conteúdo históricofilosófico no currículo dos cursos de licenciatura em física e em química da UFRN: uma análise comparativa. Caderno Brasileiro de Ensino de Física, v.28, n.1, p.229-258, 2011.

REIS, P., \& GALVÃO, C. O diagnóstico de concepções sobre os cientistas através da análise e discussão de histórias de ficção científica redigidas pelos alunos. Revista Electrónica de Enseñanza de las Ciencias, v.5, n.2, p.213-234, 2006.

REZNIK, G.; MASSARANI, L.; MOREIRA, I. D. C. Como a imagem de cientista aparece em curtas de animação? História, Ciências, Saúde-Manguinhos, v.26, n.3, p.753-777, 2019.

RIBEIRO, G.; SILVA, J. L. J. C. A imagem do cientista: impacto de uma intervenção pedagógica focalizada na história da ciência. Investigações em Ensino de Ciências, v.23, n.2, p.130-158, 2018.

SILVA, B. V. C. A natureza da ciência pelos alunos do ensino médio: um estudo exploratório. Latin-American Journal of Physics Education, v.4, n.3, p.24-34, 2010.

SILVA, B. V. C. O desenvolvimento do conhecimento pedagógico do conteúdo referente à temática natureza da ciência na formação inicial de professores de física. Tese de 
Doutorado apresentada ao Programa de Pós-Graduação em Ensino de Ciências e Matemática, Universidade Federal do Rio Grande do Norte, Natal, 2018.

SILVA, B. V. C. A história e filosofia da ciência na formação dos professores: um estudo no curso de física da UFPI. Revista Ciências \& Ideias, v.5, n.1, p. 39-50, 2014.

SILVA, B. V. C.; DE CALAÇA, F. M. S. Uma estratégia didática para discussão da concepção de ciência e do cientista com alunos do ensino fundamental. Revista de Ensino de Ciências e Matemática, v.8, n.2, p.183-196, 2017.

SILVA, B. V. C.; MARTINS, A. F. P. Uma proposta para avaliação do desenvolvimento do conhecimento pedagógico do conteúdo de futuros professores de Física acerca da temática Natureza da Ciência. Caderno Brasileiro de Ensino de Física, v.35, n.2, p.389-413, 2018.

SILVA, B. V. C.; MARTINS, A. F. P. O conhecimento pedagógico do conteúdo referente ao tema Natureza da Ciência na formação inicial de professores de Física. Caderno Brasileiro de Ensino de Física, v.36, n.3, p.735-768, 2019.

SILVA, M. L. S.; SILVA, B. V. C.; DE CARVALHO, H. R.; DO NASCIMENTO, L. A. Natureza da ciência no ensino fundamental: por que não?. Experiências em Ensino de Ciências, v.12, n.3, p. 1-30, 2017.

SOUZA, G. D. S.; SILVA, B. V. C. Natureza da Ciência por alunos de Licenciatura em Física. Latin-American Journal of Physics Education, v.7, n.4, p.1-11, 2013.

SHULMAN, L. S. Those who understand: Knowledge growth in teaching. Educational researcher, v.15, n.2, p. 4-14, 1986.

SHULMAN, L. Knowledge and teaching: Foundations of the new reform. Harvard educational review, v.57, n.1, p.1-23, 1987.

Submetido em: $\mathrm{xx}$ de $\mathrm{xxx}$ de $\mathrm{xxxx}$. Aprovado em: xx de $\mathrm{xxx}$ de $\mathrm{xxxx}$.

Publicado em: xx de xxx de xxxx. 
Caderno de Pesquisa em Ensino de Ciências e Matemática

\section{Anexo A: Sequência didática produzida pela professora}

\begin{tabular}{|c|c|c|c|c|}
\hline \multicolumn{5}{|c|}{ ESCOLA: EXCLUÍDA } \\
\hline \multicolumn{5}{|c|}{ Professora: EXCLUÍDA } \\
\hline & & $\begin{array}{l}\text { Turma: } \\
\text { 9ano }\end{array}$ & $\begin{array}{l}\text { Data: } \\
\text { 04/09/2019 } \\
16 / 10 / 2019\end{array}$ & $\begin{array}{l}\text { Duração: } \\
2 \text { horas por aula }\end{array}$ \\
\hline \multicolumn{5}{|c|}{ Unidade didática: A imagem equivocada do cientista, da ciência e de sua natureza. } \\
\hline \multicolumn{5}{|c|}{$\begin{array}{l}\text { Objetivos específicos: } \\
\text { Compreender como se constrói a Ciência } \\
\text { Compreender o trabalho do cientista } \\
\text { Identificar os diferentes trabalhos de um cientista } \\
\text { Compreender que o cientista trabalha com a ajuda de outros }\end{array}$} \\
\hline \\
\hline \multicolumn{3}{|c|}{$\begin{array}{l}\text { Conteúdos: } \\
1.0 \quad \text { - Como a Ciência é construída }\end{array}$} & & \\
\hline 2.0 & & & & \\
\hline 2.1 & \multicolumn{4}{|c|}{ - Como funciona o trabalho de um cientista } \\
\hline 2.2 & \multicolumn{4}{|c|}{ - As diferentes áreas de trabalho de um cientista } \\
\hline 2.3 & \multicolumn{4}{|c|}{ - O cientista e o trabalho em conjunto } \\
\hline 2.4 & \multicolumn{4}{|c|}{ - O cientista é apenas um homem velho? A imagem do cientista como intocável. } \\
\hline 2.5 & \multicolumn{4}{|c|}{ - O papel da mulher na ciência. } \\
\hline
\end{tabular}

Desenvolvimento metodológico:

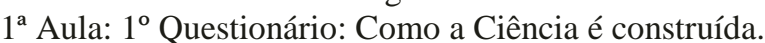

Aplicação de questionário sobre as concepções alternativas sobre ciência, com foco na visão do que é ciência para os alunos.

$2^{\circ}$ Questionário: O que é necessário para elaborar princípios ou leis científicas?

Aplicação do questionário sobre as concepções alternativas dos alunos sobre como o que é necessário para se formular uma teoria. Neste questionário, as respostas serão ditas pelos alunos em voz alta e discutidas.

\section{$2^{a}$ Aula: O trabalho de um cientista}

Etapa I

Aplicar texto base da Edição 264 "Como ser Cientista", da revista Ciência Hoje das Crianças, pedir que cada aluno leia uma parte e explique em uma simples frase o que entendeu com a parte lida.

Etapa II

Como o texto trata de forma mais aprofundada a profissão de um cientista naturalista, a proposta da segunda etapa é levar os alunos para alguma parte da escola que tenha plantas e insetos e perguntar a eles se o cientista pode trabalhar apenas com a observação.

Depois cada aluno fará um texto sobre o que entendeu.

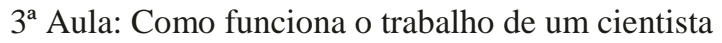

Etapa I

Realizar um experimento simples na sala de aula, chamando os alunos a participarem e ajudarem na resolução do experimento. Após isso, explicar para os alunos a necessidade que o cientista tem em trabalhar com outras pessoas, como visto durante o experimento.

Etapa II

Mostrar imagens de cientistas que realizam funções fora do laboratório e que trabalham em diferentes áreas, como por exemplo: arqueólogo, oceanógrafo, professor de ciências.

Pedir aos alunos que pesquisem e escolham uma área de pesquisa de um cientista que os interesse, para apresentar para os colegas de classe.

$4^{\circ}$ Aula: Leitura do texto.

Etapa I: Leitura de texto didático sobre a visão da imagem do cientista.

O cientista é apenas um homem velho?

Durante uma aula em uma turma do ensino fundamental, o professor de ciências tentava explicar para os alunos sobre as Leis de Newton, porém, com toda a bagunça e desinteresse dos alunos, a aula se tornava impossível. 
O professor, que escrevia no quadro e pedia por silêncio, já não suportava mais todo aquele alvoroço. Apagou o quadro, sem nem ter terminado, causando espanto nos alunos e criando uma onda de silêncio. Enquanto os alunos se entreolhavam, o professor retirava um projetor da mochila e logo o ligou na tomada.

-Eitaa! - disse um aluno chamado Pedro, ao ver a foto de um homem estranho com os cabelos assanhados.

-Newton - disse o professor - foi ele quem criou estas leis no qual eu venho tentando explicar.

- Professor, porque ele é estranho? - indagou João, outro aluno que estava muito curioso.

- Porque ele é um cientista! - respondeu Bruna, a aluna mais levada da sala.

-Nada disso! - disse o professor - ele não é estranho pelo fato de ser cientista, essa não é uma característica que define o cientista, Bruna.

- O cientista é sempre um cara velho? - perguntou Pedro.

- Não, o cientista é uma pessoa comum, com qualquer característica física, sendo novo ou velho. Qualquer um de vocês pode ser um cientista...

-Mas eu não sou homem, prôfe... - disse Bruna, com o rosto apoiado entre as mãos.

- Há um século, Marie Currie fez estudos e descobertas sobre a radioatividade, estudos que hoje nos trouxeram a magnífica máquina de raio -X, responsável por realizar exames de imagem e descobrir doenças de forma inimaginável em sua época. Marie foi uma mulher que teve muitas dificuldades na sua época, por ser mulher ela não podia estudar, mesmo assim fez a diferença com muito esforço.

A aluna ficou paralisada, sem respostas. Logo mudou-se seu semblante e ela riu, aliviada.

Pedro, muito curioso, encontrou o momento certo para fazer a pergunta que tanto queria.

-Mas professor, se os cientistas são pessoas comuns, como eles conseguem fazer tudo sozinhos? Eu acho que eles não são comuns não, eles são gênios. Ouvi a história que esse Newton descobriu uma de suas leis porque uma maçã caiu em sua cabeça... Sei não hein.

O professor riu e junto com aquela risada veio o momento em que ele jamais esqueceria, o momento exato em que ele ganhara a atenção de todos da sala, todos ao mesmo tempo esperando sua resposta e preparados para fazerem mais uma pergunta. Naqueles minutos de sua aula, ele percebeu o quanto a Ciência era importante na vida daquelas crianças e que ele nunca mais daria a mesma aula de sempre sem antes saber o que seus alunos pensavam. Ele respirou fundo e respondeu:

- A Ciência e todas as suas leis não seriam estudadas ou descobertas se não houvessem a participação de pessoas trabalhando em conjunto. Seria como se eu estivesse dando aula para as paredes e não tivesse vocês para me ensinar tudo o que eu aprendi por ensinar hoje.

Etapa II -Interpretando o texto: Atividade sobre o texto.

Aplicação de atividade sobre a interpretação do texto:

Questão principal a ser abordada:

1) Você acredita na explicação de Pedro sobre a maçã que caiu na cabeça de Newton, responsável por instruí-lo a fundamentar uma lei?

Discutir essa questão, entre outras, com os alunos em forma de círculo.

5 Aula: O papel da mulher na ciência: Vídeo sobre Marie Currie

Etapa I

Aplicação em sala sobre o vídeo "Os Grandes Personagens da História - Marie Currie”, disponível no site Youtube.

Etapa II

Aplicar questionário sobre o filme, focado na pós concepção sobre o assunto a ser estudado.

Recursos Didáticos: Sala de aula com: Quadro branco, pincel, apagador e data show

Espaço na escola: com plantas e insetos para aula prática

Avaliação: As avaliações serão:

Qualitativas: Participação dos alunos durante o decorrer das aulas e discussões.

Quantitativa: Resolução de questionários a cada aula.

Referências: SILVEIRA, A. F. et al. Natureza da Ciência numa Sequência Didática: Aristóteles, Galileu e o movimento relativo. Paraíba, 2010. 
Caderno de Pesquisa em Ensino de Ciências e Matemática

\section{Anexo B: Questionário - Representação de Conteúdo, com respostas da participante}

\begin{tabular}{|c|c|}
\hline Questões do Core & Ideia \\
\hline $\begin{array}{l}\text { 1. O que você pretende que os } \\
\text { estudantes aprendam sobre essa } \\
\text { ideia? }\end{array}$ & $\begin{array}{l}\text { Pretende-se que seja desmistificada a visão do cientista como um gênio } \\
\text { que trabalha sozinho e é anti social. A proposta é aproximar os alunos } \\
\text { à realidade de um cientista e instigar o trabalho em grupo, ou trabalho } \\
\text { coletivo. Para isso, um questionário servirá como norte do } \\
\text { desenvolvimento das aulas, em que será trabalhado mais a fundo o que } \\
\text { eles possuem mais dificuldade. }\end{array}$ \\
\hline
\end{tabular}

2. Por que é importante para o estudante aprender essa ideia?
Essa ideia é importante para que seja trabalhada a concepção de cientista que cada aluno tem, focando na desconstrução dessa concepção, caso esteja equivocada. É importante ser trabalhada na sala de aula para que a própria compreensão da ciência seja facilitada. Logo que, se a profissão de um cientista for entendida como difícil, a ciência também se tornará difícil de ser compreendida.
3. O que você sabe a mais sobre essa ideia?
Além de tratar sobre o trabalho coletivo de um cientista, seria interessante também mostrar que sem alguns cientistas não tão conhecidos, não teríamos todo o desenvolvimento de leis e teorias. É interessante tratar dessa questão mostrando aos alunos alguns nomes desconhecidos na ciência e mostrar sua contribuição em algumas teorias.

4. Quais são as dificuldade e limitações ligadas ao ensino dessa ideia?

Dentre as dificuldades e limitações, podemos citar a própria mídia e os livros didáticos que tratam da imagem do cientista de forma equivocada, como um cara velho de cabelos assanhados e louco, trabalhando sozinho em um laboratório. Essa ideia é vislumbrada pelos alunos, causando apatia pela ciência.

5. Que conhecimento sobre o pensamento dos estudantes tem influência no seu ensino sobre essa ideia?
Um fator que dificulta muito a aprendizagem desses alunos com relação à imagem equivocada do cientista, é por exemplo, abrir o livro didático e perceber alguns erros conceituais que incentivam ao aluno a continuar na crença de que o cientista é alguém extremamente inteligente e diferente.

A forma como a própria escola muitas vezes trata a ciência, ou como a família entende a ciência, fazendo com que o aluno seja influenciado e pensar que a ciência não é para todos ou que precisa ter nascido gênio, para se trabalhar sozinho e ser um cientista.

Não permitir que os alunos se percam durante a explicação, não permitir que percam o foco e sempre procurar outras formas de abordar um assunto, sem ser somente na sala de aula escrevendo no quadro. É necessário abordar problemas diferentes com estratégias diferentes.

Aplicar questionários e fazer debates em círculos, para que todos se sintam à vontade e possam focar na ciência e no cientista como algo natural. Propor também aos alunos a trabalharem em equipe, seja no laboratório, seja na sala de aula ou durante pesquisas em grupo. Aproximando sempre a ciência ao aluno e o avaliando a todo momento, para que quando ocorra um equívoco por parte do aluno, seja planejada uma nova dinâmica para resolvê-lo. 